University of Nebraska - Lincoln

DigitalCommons@University of Nebraska - Lincoln

Faculty Publications, Department of Child, Youth, and Family Studies

Child, Youth, and Family Studies, Department of

3-2009

\title{
Engaging Latinos in Culturally Specific Educational Programming: A Multidisciplinary Approach
}

\author{
Paul R. Springer \\ University of Nebraska-Lincoln, pspringer3@unl.edu \\ Cody S. Hollist \\ University of Nebraska Lincoln, chollist2@unl.edu \\ Karen Buchfink \\ Crete Public Schools, Crete, Nebraska
}

Follow this and additional works at: https://digitalcommons.unl.edu/famconfacpub

Part of the Bilingual, Multilingual, and Multicultural Education Commons, Family, Life Course, and Society Commons, and the Race and Ethnicity Commons

Springer, Paul R.; Hollist, Cody S.; and Buchfink, Karen, "Engaging Latinos in Culturally Specific Educational Programming: A Multidisciplinary Approach" (2009). Faculty Publications, Department of Child, Youth, and Family Studies. 62.

https://digitalcommons.unl.edu/famconfacpub/62

This Article is brought to you for free and open access by the Child, Youth, and Family Studies, Department of at DigitalCommons@University of Nebraska - Lincoln. It has been accepted for inclusion in Faculty Publications, Department of Child, Youth, and Family Studies by an authorized administrator of DigitalCommons@University of Nebraska - Lincoln. 


\title{
Engaging Latinos in Culturally Specific Educational Programming: A Multidisciplinary Approach
}

\author{
Paul Springer \\ Cody Hollist \\ University of Nebraska-Lincoln \\ Karen Buchfink \\ Crete Public Schools, Crete Nebraska
}

\begin{abstract}
Results from the 2000 United States census highlighted that the Latino population had exceeded the African American population as the largest U.S. minority group. Furthermore, during the past 20 years, migration patterns for Latino families have spread throughout the West, Midwest, and South and not merely in the border states. To meet the rising educational and human service needs, professionals have sought to develop programs that are effective at helping the Latino populations. This article presents a theoretical model for engaging Latinos in family and consumer science education and outreach programs. The model was designed for family and consumer science educators and draws from both the education and human service literature. A case study is used to outline the application of the model and suggestions for implementation are described.
\end{abstract}

Keywords: engaging Latinos; culturally specific programs; teacher family involvement; parent education; parent teacher programs

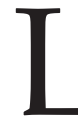

atinos are among the fastest growing populations in the United States. During the 2000 census, it was revealed that the Latino population surpassed African Americans as the largest minority group in the United States (U.S. Census Bureau, 2001). The census bureau projects continued Latino growth in part because of immigration, but primarily because of large families among the Latino population. With this population growth, comes a need for more culturally sensitive communities and schools to meet the new demands that are inherent in working with Latino families. In fact, it is becoming evident that more and more youth will be growing up in bicultural environments with higher numbers of Latino families than any U.S. generation of the past (Sugunro, 2001; U.S. Census Bureau, 2003). Consequently, educators must be ready and knowledgeable in how they can effectively change the face of their teaching to meet the needs of a changing population (Von Secker \& Lissitz, 1999). Our belief is that family and consumer science teaching takes place not only in the classroom but also through outreach as they engage Latino families in community-based activities and educational programming.

Correspondence - Paul Springer, PhD, Department of Child, Youth, and Family Studies, Marriage and Family Therapy Program, University of Nebraska-Lincoln, Lincoln, NE 68588-0236; tel 402-472-1656; fax 402-4729170; email pspringer3@unl.edu. Cody Hollist, PhD, Department of Child Youth and Family Studies, University of Nebraska-Lincoln, NE 68588-0236; tel 402-472-8105; fax 402-472-9170; email chollist2@unl.edu. Karen Buchfink, School Counselor, Crete School District, Crete, NE. 
Because of the importance of parent involvement in education, there is an increasing push to involve Latino parents in educational programming and the need to develop culturally appropriate programs (Civil, Bratton, \& Quintos, 2005; De Gaetano, 2007). Education research has looked at ways of involving parents in their child's educational process but little exists that outlines methods of developing community outreach for family and consumer science programming within the Latino community. The struggles seen in the process of engaging Latinos in these types of programs are also experienced in the human service field (Delgado, 1998; Maldonado-Mulina, Reyes, \& Espinosa-Hernandez, 2006). Human services as well as community programming have produced literature on engaging families in community-based programs (Auerbach, 2004; Cooper, 2002), which we believe may be beneficial as a foundation for more effective family and consumer science outreach programming. The purpose of this article is to blend the research from human services (e.g., social work, family therapy, mental health, community programming, etc.) with the needs of family and consumer science outreach programs to outline a method whereby educators may effectively develop educational/school programs that engage Latino families.

The intent of this article is not to outline the link between education and emotional/mental health needs as that premise has been supported in past research. Evidence exists linking childhood emotional distress and poor academic performance (Gonzales, Tein, Sandler, \& Friedman, 2001). Inversely, research has also identified the tremendous stress that is caused by struggling academic performance (Altermatt, 2007). That given, the goal of this article is to provide a method for engaging Latino families in outreach educational programs, built on the human service literature about engaging Latino families in community-based programs. It is our belief that the similarities which are outlined in this article suggest an overlap in the challenges faced by education and human sciences as they relate to working with Latino families.

The disparity between services needed and services received for Latinos is a concern for both educators as well as human service professionals. Engaging Latino families in programs continues to be a challenge at all levels of programming (Delgado, 1998). Although different programs have been used in both education and social services, the literature has not made explicit which, if any, barriers to successful programs are similar between social services and education. Research from both fields has identified the challenge of involving parents in programs (Auerbach, 2004; Machen, Wilson, \& Notar, 2005), both have identified some factors that affect engagement (Weaver, 2007), and both bodies of literature are strikingly similar. These similarities exist at three different levels: First, the communities' need for programmatic assistance; second, the factors that act as barriers for Latino family engagement; and finally, some programmatic similarities between education and human sciences. Bringing these similarities together, we will then draw from human service literature regarding community-based program development to outline a guide to developing culturally and community-specific educational outreach curriculum for Latinos.

\section{Needs Not Equal to Services}

Similar rates of mental illness exist between Latino and Caucasian children and adolescents (Folsom et al., 2007). The educational need for Latino and Cau- 
casian children is also inherently similar with both groups needing high-quality education. For example, educational success is seen as a key predictive factor for economic stability within all cultural groups, with the minimum standard of educational achievement as completion of a K-12 education. Research related to high school graduation rates indicates that dropout rates vary across cultures, with Latinos twice as likely to drop out of school than either African American or Caucasian students (National Center for Education Statistics, 2001). About 28\% of Latino adolescents in the ages between 16 and 18 dropped out of school in the year 2000, with only 13\% of African Americans and 7\% of Whites dropping out in the same time period. Latinos born outside the United States were the highest risk category and were 3 times more likely to drop out of school (44\%) than were first$(15 \%)$ or second-generation (16\%) Latinos (National Center for Education Statistics, 2001). Consequently, the immigrant Latino population is difficult to engage in educational and human service programs. Despite these staggering statistics, research has shown that when Latino parents are involved in their children's academics, they are not only more likely to stay in school but also to excel academically (Riggs \& Medina, 2005). This illustrates the need for family engagement with the educational system. Research also highlights the challenges often felt in the educational system in providing sufficient education to the Latino population. Hence, although the need for education is the same for Latinos and Caucasians, there is a disparity between the levels received between groups.

Just as with the need for education, the need for social assistance (i.e., mental health, economic assistance, housing, job training, etc.) is similar between Latino and non-Latino groups. Furthermore, Latino youth are about 2 times less likely to receive services for mental illness than are Whites, with foreign born Spanishspeaking clients the least likely to receive services (Alegría et al., 2002). Not only are Latinos unlikely to receive services but also about one half of all Latinos who enter therapy drop out after the first session, making successful treatment unlikely if not impossible (La Roche, 2002). These examples are typical of the body of literature that outlines the disparities between Latinos and non-Latinos in the use and success of human service programs. Responding to the problem requires looking at the factors that affect successful engagement and retention in both academic and human service programs.

\section{Engagement}

Both education and social services have been concerned with the process of engaging Latino families in their programs. This initial engagement is crucial to the success of both areas of service. For example, the quality of the therapist/client relationship in therapy has been found to predict 30\% of the client change (Lambert, 1992). This impact is twice that of the techniques used by the therapist. It is estimated that the quality of this relationship is established within the first few sessions (Bachelor \& Horvath, 1999).

Similar outcomes are found with engagement of parents and families in educational programming (De Gaetano, 2007). The potential positive impact of collaboration between social services and educational institutions is greatest for highrisk youth (Massey-Stokes \& Lanning, 2003). This is seen especially among Latino youth, who are much more likely to drop out of school, struggle with academic 
achievement all the while experiencing similar rates of emotional distress as their Caucasian counterparts (Alegría et al., 2002; La Roche, 2002; National Center for Education Statistics, 2001). It is because of this interface between education and social services that a clear understanding of how to engage families in both settings is needed.

Engagement is more than just participation. Although participation is a necessary first step, it is not sufficient. Engagement entails both attendance at and involvement in the programs. This involvement is a higher predictor of success of the program than is attendance (Santisteban et al., 1996). In many cases, youth and their families are enrolled in programs because of some risk they are experiencing. These families feel pressured into participation and are not invested in the program nor do they believe it will help. It thus becomes important to identify the barriers that keep families from engaging in programs. Understanding and explicitly addressing these barriers are important for educators developing outreach programs.

\section{BARRIERS TO ENGAGEMENT}

Studies are consistently clear that there are unique barriers that contribute to Latinos underuse of education and social services (Ho, Rasheed, \& Rasheed, 2004; Turner, Wieling, \& Allen, 2004). However, it is important to realize when presenting these barriers that it would be culturally insensitive and professionally unsuccessful to assume that what will work for one Latino group (e.g., Mexican immigrants) will work for others (e.g., Cuban and Puerto Rican immigrants), as their culture, dialect, and circumstances for immigrating are vastly different. Therefore, failure to adequately understand within-group differences among Latinos would cripple even the best educational and human service programs and their capacity to reach the very people they hope to help.

\section{Within-Group Differences in Latino Immigrant Families}

One of the challenges and dangers when attempting to engage Latino immigrant families is that Latinos are often viewed as coming from one large homogeneous group (Cauce \& Domenech-Rodriguez, 2002) rather than the heterogeneous group that they are. In fact, Latino immigrants come from a variety of countries, such as Mexico, Puerto Rico, Cuba, El Salvador, Argentina, Chile, and Brazil, with very unique historical and cultural traditions (Cauce \& DomenechRodriguez, 2002; Falicov, 1998). As a result, there are unique differences that exist not only among one nation to another but also from one cultural group to another (Falicov, 1998). Usually, among Latin American countries, there exists a distinct amalgamation of Hispanic values and native/indigenous languages and cultures (Falicov, 1998). Consequently, in most Latin American countries, one can find at least three groups: (a) the indigenous groups, (b) the mestizo group (which is a mixture of the indigenous and Spanish blood), and (c) the pure descendents of Spain (Falicov, 1998). This illustrates the dynamic differences that exist between cultures typically described as Latino. Consequently, although the barriers faced by Latinos may appear similar at "face value," between-group differences will drastically affect how these families experience them. 
The often silent, yet surprising between-group differences can be seen in the prejudice between different Latino immigrants (e.g., Mexican Americans, Puerto Rican Americans, and Cuban Americans; Falicov, 1998). Although these groups share the same language, racial and cultural differences affect the intragroup interactions. Shorris (1992) suggests that the prejudice interactions are based on myths about prestige of national origin and race among the three Latino groups. However, it also clearly highlights cultural differences between these groups; differences that need to be understood to effectively address within-community needs.

Furthermore, even within Latin countries, there exists a wide range of racial, ethnic, and cultural groups, much like what is found within the United States (Ortiz, 1995). These vast cultural traditions and heritages among Latin American countries make it easy to recognize how important it is for program developers to understand the immigrant community they are attempting to engage. In addition, it provides a compelling argument for the need to move beyond generalizations about Latinos, and make efforts to understand the local subcultures in which these families live. It is believed that as programs are better able to recognize the local subcultures, barriers, and needs of these families, they will be able to develop culturally informed and culturally sensitive programs that can be successful in engaging immigrant families (Hurtado, 1995; Uttal, 2006).

\section{Acculturation and Adaptation}

One of the primary sociocultural barriers faced by immigrant Latino families is related to issues of acculturation and adaptation. It is important to understand that for many families, the process of immigration and acculturation is paralyzing (Flores \& Carey, 2000). Families are often struggling with how to adapt to a culture whose values are very different from their own, while attempting to maintain important aspects of their heritage (Falicov, 1998). Vega (1995) describes this struggle as being related to the loss of important social support networks. This sudden lack of family support and acceptance of traditional cultural practices appear to compromise many Latino immigrants' ability to effectively and efficiently adapt to their new surrounding (Castro, Barrera, \& Martinez, 2004). Consequently, it is not uncommon for immigrant families, struggling with how they fit into the new dominant culture, to begin experiencing various forms of marginalization. This is often because of their inability to speak English, their educational and economic levels, and their sociocultural values that are often in conflict with the mainstream culture (Chrispeels \& Rivero, 2001).

\section{Language}

One of the most pressing barriers to family involvement in community programs documented in the literature is rooted in the parents' inability to speak or understand English and/or the program's inability to provide services in Spanish (Ho et al., 2004; Quezada, Diaz, \& Sanchez, 2003). Although much has been written about the language learning of children of immigrants in the United States (Gutierrez, Baquedano-Lopez, \& Alvarez, 2001; Laliberty, 2001; Worthy, 2006), it is clear that the parents of these immigrant families often struggle in developing a degree of proficiency in English that would facilitate the comfort needed to engage in educational and social service programs. Furthermore, many immigrant families remain in homes, jobs, or communities that shelter them from the neces- 
sity of learning English (Worthy, 2006). Without service provision modifications in place, parents often become dependent on their children, and may even overburden them with multiple responsibilities such as translating in stores, clinics, and other public arenas as well as maintaining other household chores such as babysitting (Falicov, 1998; Worthy, 2006).

\section{Economic Factors}

Latino immigrant parents' lack of proficiency in English further compounds their ability to find and maintain gainful employment. As a result, parents of immigrant Latino families often have to tolerate a heavy work schedule, including holding two or more jobs, working overtime, accepting low wages, and withstanding exploitative working conditions (Falicov, 1998) just to afford the basic needs for their families. Many times, these parents have little hope of job advancement because of the language barriers that exist. Consequently, these families are faced with unique economic hardships that infringe on their ability take part in community, educational, and social service programs (Powell, 1995; Quezada et al., 2003). In fact, research clearly shows that immigrant parents long to be a part of their children's educational lives (Ada \& Zubizarreta, 2001; Worthy, 2006). However, without financial freedom that is afforded to other middle-class families, immigrant Latino parents often lack the time and the financial ability to leave work to attend meetings that are "expected" by the schools or social service agencies, such as parent teacher conferences (Powell, 1995). Even in instances where families could benefit from programs, such as taking English as a Second Language (ESL) classes, the financial challenge these families face paralyze their capacity to participate.

\section{Trust}

To facilitate a higher degree of participation in educational and community programs, there is a need to first overcome the barrier of distrust that immigrant Latino families often feel toward outsiders (Powell, 1995). In fact, immigrant Latino families have often received mixed messages about virtually every aspect of their life in America (Arroyo, 1998; Worthy, 2006). For instance, the immigration backlash of the 1990s was based on the assumption that Latinos are taking jobs of U.S. citizens, wanting free handouts, not contributing to the U.S. economy, and are not assimilating to mainstream society (Arroyo, 1998). Consequently, many immigrant families are resentful of these sentiments and believe that educational, community, and human service programs harbor some degree of prejudices that create a deep sense desconfianza or mistrust (Falicov, 1998). As a result, Latino parents inherently distrust the intentions of program developers, as they perceive that their role is not particularly valued or respected (Powell, 1995). Therefore, programs need to be deeply concerned with developing trust with these families by focusing on building interpersonal relationships. In fact, literature describes the necessity to overcome this barrier by applying concepts of personalismo that are centered around building relationships of respect, dignity, and kindness (Bean, Perry, \& Bedell, 2001; Falicov, 1998; Ho et al., 2004). This process and person-focused approach are critical in developing confianza (trust) and in breaking down perceived prejudices necessary for interfacing educational and social services providers with Latino families. 


\section{Immigration}

Desconfianza as described by Falicov (1998) and Ho et al. (2004) also filters into the educational and social service climate of parent/teacher and therapist- family relationships, respectively. In fact, recent literature is clear that Latino parents recognize and desire to be more active in their children's education and life (Chrispeel \& Rivero, 2001; Powell, 1995; Quiocho \& Daoud, 2006). However, often these families are apprehensive in engaging schools, community agencies, and social service programs because of their documentation status. Naturally, these families are fearful of detection and the threat of deportation (Falicov, 1998) and avoid contact with schools or community programs as a means to avoid detection. This avoidance perpetuates a lack of knowledge of the procedures for child enrollment and lack of understanding of the expectations that schools and communities have for family and child participation in these programs. The larger social debate regarding immigration has implications for families who have documentation because of the prejudice they often experience by individuals treating them as if they were in the United States "illegally." The U.S. census estimates that more than $77 \%$ of the Latinos living in the United States have proper documentation (U.S. Census Bureau, 2001, 2003); this means that the negative stereotypes are incorrectly implicating a majority of the population. Naturally, this creates unique challenges for those both with and without documentation when developing educational and social service programs that can not only address these families' needs but also seek to develop trust in the families.

\section{Barriers From Misperceptions of Professionals}

The education literature is also clear that teachers often hold negative perceptions of immigrant Latino families. Unfortunately, these perceptions are almost always based on misunderstanding and miscommunications between parents and teachers (Ada \& Zubizarreta, 2001; Palermo, Hanish, Martin, Fabes, $\&$ Reiser, 2007). One of the primary misperceptions is that immigrant families do not care about their children's education (Ada \& Zubizarreta, 2001; Chrispeels \& Rivero, 2001; Quiocho \& Daoud, 2006; Valdés, 1996). This is often based on the assumption that if Latino parents had high hopes for their children, they would express them similarly to European American parents (Ada \& Zubizarreta, 2001). When in actuality, immigrant Latino families often lack sufficient understanding of the school system to know that they not only have a right to participate but are also expected to be assertive in this process (Chrispeels \& Rivero, 2001). Therefore, it is important to understand the Latino concept of a parents' role in their child's education.

There are two perspectives that are often shared by Latino cultures. First is the pervading belief that parents are not to interfere with the teaching that occurs at school (Quezada et al., 2003). In fact, Latinos have such a high level of respect for educators; they often "feel that interfering with school activities would be counterproductive" (Quezada et al., 2003, p. 32). Consequently, they are not as vocal in asserting their beliefs in the educational process. Second is the belief that the parents' role is to create a strong foundation in the home (Ada \& Zubizarreta, 2001; Valdes, 1996). This foundation also includes the teachings of morals, beliefs, etiquette, respect, persistence, and manners (Ada \& Zubizarreta, 2001; Falicov, 
1998). With this understanding, it is critical that parents are educated about expectations and program requirements to give permission for their participation at a higher level.

\section{Family Structure}

Before discussing the general structures in Latino families, it is important to state that family structure in all cultures is affected by many factors such as country of origin, socioeconomic factors, education, and acculturation (Castro et al., 2004; Falicov, 1998; Powell, 1995). Consequently, family consumer science professionals will find variations of hierarchical structures, suggesting caution when applying these characteristics to all individual cases. With that understanding, the Latino literature in the social service arena has described hierarchy as both gender and generational (Ho et al., 2004). In traditional Latino families, the father occupies the role as the authority figure, with the wife and the children's roles to follow. This hierarchical structure has often been linked to the term "machismo," which is understood by the Anglo culture to mean domineering, insensitive, and controlling (Falicov, 1998; Ho et al., 2004). Conversely, authors have argued that the Latino meaning of machismo should not be pathologized, as it can be positively equated to a man being an honorable husband and father, responsible for providing and protecting one's family (Bean et al., 2001; Falicov, 1998). This concept of hierarchy has important implications for educational and social service, as it speaks to the importance of appealing first to the father figure, as a necessary part in facilitating engagement (Bean et al., 2001; Falicov, 1998; Powell, 1995). In fact, fathers play an important role in issues of family honor and decisions about what occurs with the family unit (Bean et al., 2001), and should not be excluded from this process. Failure to engage fathers may lead to minimal involvement by the family.

Despite the emphasis of a man's roles as leader and decision maker in Latino families, it would be inaccurate and unwise to underestimate the mother's role in the family. Although Latina women and mothers are not recognized as the head of the family, they are widely viewed as the heart and soul (Madding, 2002). In fact, the role of mother carries considerable status and respect, as they are primarily responsible for raising and caring for the children (Falicov, 1998). Although this role may be viewed as restrictive and oppressive, by mainstream Anglo culture, it represents and validates the marriage. In many ways, wives covertly run the home behind the scenes, while publicly supporting the husband (Ho et al., 2004). Consequently, involvement by both father and mother in educational and social services will provide the greatest likelihood of success.

\section{Collectivism Versus Individualism}

Finally, sociocultural differences in the way family unit is structured are a critical component that if misunderstood may limit success when engaging these families. Latino families come from a rich collective or family-oriented culture (Falicov, 1998). Latinos use the term famalismo to reflect the cultural value in which family relationships are highly esteemed and individual identity is tied to those associations (Bean et al., 2001; Falicov, 1998; Ho et al., 2004). This collectivistic worldview stands in contrast to the dominant Euro-American (non-Hispanic) in- 
dividualistic worldview in which the emphasis is on individual ownership and competition (Bitar, 2007). As such, many family functions, such as caretaking, problem solving, and financial responsibilities are traditionally shared among family members (Falicov, 1998).

Typically, Latino families also define who is included as family with a much broader lens than the dominant Euro-American culture. For example, many Latino families include grandparents, aunts, uncles, and cousins as part of their immediate family. As a result, children who come from divorced, widowed, or orphaned families may actually be taken in by relatives and raised as their own with the seamless perception that the individual is and has always been a member of the family (Falicov, 1998). Consequently, ascertaining key family figures that may not "traditionally" be viewed as part of the dominant Anglo culture is critical in successfully engaging these families. In fact, recent human service research has documented that the failure to involve the family in psychotherapeutic treatment may lead to additional family-functioning problems instead of eliminating them (Szapocznik \& Prado, 2007).

In addition, the context of familismo acts as an immigrant's family main social support group and creates a sense of cohesion and solidarity. In fact, familismo dictates that parents guard family conflict or problems from outside inquiry (Falicov, 1998). Consequently, in safeguarding the family's problems and out of respect for auxiliary parties, immigrant families feel compelled to handle behavioral and or academic problems privately. This may often be misinterpreted by teachers and therapists negatively, and leads to incorrectly labeling these parents as inattentive or unresponsive to what is occurring in their child's life (Chrispeels \& Rivero, 2001).

\section{Bridging Expectations and Situations}

One of the unique challenges in engaging Latino immigrant families is the need to bridge the gap between what educational, community, and human service agencies expect to encounter when working with Latino families and the reality of the family situation. To do this, these organizations need to be educated in how to be more culturally competent and sensitive when engaging this population (Hernandez, Isaacs, Nesman, \& Burns, 1998). Cross, Bazron, Dennis, and Isaacs (1989) defined cultural competence as "a set of congruent behaviors, attitudes, and policies that come together in a system, agency or among professionals, and enables that system, agency or those professionals to work effectively in cross cultural situations" (p. 13). In other words, cultural competence is an action-oriented concept, in which people, regardless of race or ethnicity, are capable of achieving (Hernandez et al., 1998). As a result, cultural competence should be conceptualized as a developmental process that evolves over time (Hernandez et al., 1998).

Uttal (2006) makes the case that becoming culturally competent requires a model of cultural engagement that goes beyond adapting programs, building community relationships, and removing barriers (Uttal, 2006). In fact, professional cultural competency entails a degree of sensitivity in evaluating community needs, which can inform program curriculum and deliverance. Consequently, a degree of cultural immersion and engagement by human service providers is implied within the cultural competent practice literature (Hernandez et al., 1998; Uttal, 2006). Therefore, developing community-specific programs in conjunction 
with local Latino families is necessary to facilitate optimal program effectiveness to motivate and sustain engagement by Latino immigrants in educational community and social service programs (Castro et al., 2004).

There are essentially three levels of program specificity that categorize outreach efforts in education and social services. These categories were articulated by Uttal (2006) when talking about different degrees of cultural sensitivity. In this article, they will be used to provide the foundation for the discussion about how to develop effective programs for Latino families, regardless of programmatic intent. The first level is cultural adaptation, the second level is cultural specific, and the third level is community-based programs. Although these are described categorically, we recognize that in reality three different and often parallel processes exist that blends together in developing effective programming. Furthermore, each of these levels contributes to successful programmatic development.

\section{Culturally Adapted Programs}

The literature is clear that to create and/or develop culturally effective programs, there is a need to adapt curriculum that can take a more culturally competent stance to achieve success (Bartolome \& Balderrama, 2001; Diaz \& Florez, 2001; Uttal, 2006). Cultural adaptation is a process of modifying the delivery format of a previously used program to fit with another group or population (Uttal, 2006). One of the most common forms of adaptation spoken in the literature is modification of program content, or what Castro et al. (2004) describe as cognitive information processing. This requires structural changes in the program that makes the services visible and assessable to the target population. This inherently requires community agencies and human service providers to account for age, developmental level, and language barriers of the participants. Consequently, programs will need to translate materials into Spanish (Uttal, 2006) as well as offer delivery materials or services entirely in the participants' native language. Next, the process of recruiting families may need to be modified in a way that advertises to the Latino community, including providing proper incentives to increase enrollment (Gross, Julion, \& Fogg, 2001). For example, professionals may find it more effective to recruit Latinos by advertising in Latino churches, Latino markets, and Spanish newspapers instead of primary newspapers or calling lists.

Although overcoming the language barrier is the first hurdle that needs to be overcome, it is not sufficient to be successful (Uttal, 2006). Language translation is a delivery change but does nothing to modify content for specific groups. Facets of human service programs need to adapt for cultural appropriateness to respect the target's cultural practices (Hernandez et al., 1998), subsequently increasing cultural comfort. Therefore, awareness of the dynamics of cross-cultural interactions can assist in preventing "cultural discomfort" (Uttal, 2006, p. 252), which is vital in increasing retention and engagement of participants. In addition, programs should be sensitive to the educational diversity among Latino families (Ortiz, 1995) as well as cultural norms of the group (Falicov, 1998). For example, exercises that require a lot of writing, or that ignore the gender and social hierarchical structure, would undermine the retention of the group as well as possibly offend the cultural beliefs of those participating (Uttal, 2006). In other words, human service programs should be sensitive in using examples that are meaningful, appli- 
cable, and culturally relevant to the participant's life. In addition, these programs should be sensitive to the educational level and cultural norms of the group.

\section{Culturally Specific Programs}

Making programs culturally specific entails transcending language and practice patterns of a cultural group; moving beyond "surface structure" (Castro et al., 2004, p. 43) to achieve the depth necessary to incorporate Latinos core values and beliefs in the program implementation. Castro and colleagues (2004) further described this as affective-motivational adaptation. In other words, programs need to adapt activities that would create cultural conflict or resistance among the groups' values or traditions. For instance, parenting programs that take a childcentered approach or assertiveness programs that teach youth to express themselves openly (Castro et al., 2004; Uttal, 2006) fail to understand the collectivistic ideal in which family relationships are highly valued and individual identity is tied to those associations. Additional examples of content changes in programs would include recognizing and respecting the hierarchical structure of Latino couples, and the focus they place on parenthood rather than partnerhood (Falicov, 1998). Consequently, programs should understand the value systems they will be accessing and engaging, and respecting these values and worldviews in not only the material they present but also how they present it.

\section{Community Based}

Although culturally adapted and specific programs are essential components in developing and engaging Latino families in human services, this is often not enough (Uttal, 2006). In fact, one may assume that by addressing the barriers of language, recruiting procedures, and sociocultural differences that this would lead to better engagement because, in fact, the program developer has made cultural modifications as have been identified by literature. However, although these factors may help, it may not necessarily increase the engagement of these families, as these programs fail to identify the specific needs of the community (Gutierrez- Mayka \& Contreras-Neira, 1998).

Often ultimate success of a program hinges on the ability to evaluate and understand the needs of the community one is attempting to serve (Greenbaum, 1998; Gutierrez-Mayka \& Contreras-Neira, 1998). Where many professionals fall short is this final step of looking beyond generalizable characteristics of Latinos (Cauce \& Domenech-Rodriguez, 2002; Falicov, 1998). Even within Latinos from the same country of origin, there are often vast differences in regard to needs (Ortiz, 1995; Shorris, 1992). This is critical, as many programs assume that target populations come in with a certain knowledge base as outlined in some written text about said population, or that certain basic family needs are securely in place (Uttal, 2006). However, without assessing the community's characteristics, mismatches between programs and target populations will be unacknowledged, thus undermining program effectiveness.

Ultimately, the responsibility falls on the program designers to explore the community, understand its indigenous structure, and determine the most effective ways to make contact with and to gain trust of its members (Greenbaum, 1998). This step is one of the fundamental principles of cultural competence, as 
one works in concert with the community liaison's in which services are provided (Greenbaum, 1998); which can have a profound impact on program effectiveness. We recognize that for many educators or social service professionals, this is a daunting task. In many cases, well meaning professionals have recognized a need in the community and are trying to do their best to help but do not have previous experience working with the demographic changes currently occurring in the United States.

\section{PRACTICAL APPLICATION AND CASE EXAMPLE}

Because the intent of this article is to provide a useful model for educators to establish culturally effective programming, practical application is an important component of the model outline. To help illustrate how to apply these principles in a real setting, a case example will be used. This example is a description of a program developed and used by one of the authors of this article. The purpose of the program was to inform Latino parents about the system of higher education in the United States, including steps to prepare for higher education, the impact of higher education, methods of paying for higher education, and the role of parents for students seeking higher education. This author is a school counselor and became involved in the program following a failed attempt at reaching out to the Latino community by a national organization whose sole mission is to help students transition into college. This organization, which we will call "Project Help" (the name has been changed to protect organizational identity), has a series of nationally acclaimed programs developed to help students and families understand the university admissions processes, financial aid, housing, and other universityrelated topics. Our author was contacted by this organization to assist in the delivery of one program in the local community.

Project Help had taken many steps to create a culturally sensitive program that implemented culturally adapted and culturally specific modifications to reach out to the Latino community. This included translating and providing presentation materials in both Spanish as well as having bilingual presenters. To further adapt to the population they wished to present to, they advertised the presentations in locations that were frequented by Latino families (i.e., Latino markets, Latino churches, Latino business, etc.).

In addition, Project Help moved beyond cultural adaptation by identifying important culturally specific issues to address in their presentations. First, they made extra efforts to talk to the parents about family solidarity in terms of their children living away from home. They also made explicit efforts to include the fathers in the discussion as they knew they were an important figure in family decision making. In fact, this program went to great lengths to reduce cultural conflict or resistance among the Latinos families, while incorporating their values in their presentation style and language. However, despite all of these efforts, the program was not well received by the Latino community. This was surprising to the presenters as the modifications they had made to their program had given them confidence that they had produced an important and helpful set of materials. It is important to note that programs that produce ineffective materials are often portrayed as insensitive or uncaring; this was not the case with Project Help. In fact, 
it is our contention that it is not the case with most program developers. Rather, these programs stop short of being truly culturally successful and useful for the local Latino community by not making their program community based.

It was recognized that although the presentations from Project Help were exceptional, additional foundational information was needed for the community. As a result, the author felt compelled to go to the very people she was trying to help to figure out what they needed to better understand higher education. This had two impacts, a community-based presentation and unintentionally, a more firm relationship with members of the Latino community.

Because of these outreach efforts, it became clear that many Latino families lacked a more foundational introduction to the higher education system in the United States as well as what the expectations are of families and schools in preparing students for college. Consequently, this was included in the final community- based program, aimed at increasing understanding and basic knowledge of the educational system. The presentation addressed many of the "taken-forgranted" assumptions about high schools and universities in the United States. It also addressed issues such as "why it is important to get a college education," differences between 2 and 4 year Universities, and required high school courses and needed grades for students to be eligible to go to college. This presentation was received very well in the community, as it met these families where they were at; thus, providing the necessary foundational knowledge requisite for families to be engaged in the educational process. In addition, it forged a stronger bond between the Latino community and the community programmer. Many Latino families echoed their sentiment that they felt that their needs and unique challenges were not only understood by the community program but were also specifically addressed in a helpful and non-demeaning way.

Like many other programs, Project Help had taken important steps and used valuable resources in making their material useful for the Latino population in general, but not for this community specifically. We believe that this final stage of community-specific modifications is the most neglected and yet the most significant in terms of effectiveness. Many professionals are committed to developing programs in an effort to meet the needs of Latinos but fail to understand the unique needs of their local Latino community. Furthermore, we acknowledge that cultural adaptation and cultural specification are the safest methods of program modification/development because they do not require the professional to take interpersonal risks needed to engage with the Latino community. To facilitate this often daunting process, we would like to suggest several methods of reaching out to the local community. This list is not meant to be comprehensive, and in each case, the professional must think about specific circumstances within his or her community and take those into account when engaging the Latino population.

There are likely many factors that impede educators from reaching out to their local Latino community. However, as we talk to educators, two seem to be very common: Time and nervousness about not knowing how to develop a relationship with the Latino community. We propose that although outreach may appear to require significant investment on the part of the professional, it may in fact save time in the long run. As professionals verify with the local communities the best methods of meeting their needs and integrate those suggestions into program developments, it may eliminate programmatic failure, additional modifications, and redelivery. These integrations may also improve outcomes, strengthen 
group engagement, and make better use of professional resources. This justification for basing programs on the community may be logical and we believe important, but it still does not eliminate the struggle many educators feel about how to develop relationships and get feedback from the local community.

Educators have also told us that they feel nervous because they do not want to appear unknowledgeable, prejudice, or offend others. Being conscientious about the point of entry into the Latino community can ease many of the concerns regarding negative responses from families. One method of calculated community entry is to make a list of local Latino institutions and/or leaders in the Latino community. These institutions may be formal or may be informal. Some very important community leaders often do not occupy explicit positions. Some common leaders may also be other local educators at both a primary and secondary level, leaders of local churches, local business owners, professionals in the community, ethnic community organizations, translators, and agencies that provide services to the Latino population (e.g., health clinics, Latino markets, restaurants, job sites, etc.). Educators can use this list to identify who they should talk to and how that person should be approached (i.e., phone, in person, e-mail, or introduced by another individual).

The next step, how to approach the individual, can be difficult as many people find calling a stranger blindly and asking for help uncomfortable and daunting. It is our experience that most community leaders appreciate collaborative efforts and are more than willing to give feedback to local professionals on program development. In an effort to assist in this initial outreach, we have developed an outline of some questions that may be used to initiate the conversation. We have developed these questions from our experiences working with Latinos. All the authors of this article are Caucasian, and each has worked with Latinos for several years (ranging from 9 to 26 years). Each has been immersed in a Latino culture, is bilingual, and has effectively worked with Latinos professionally. By drawing from these experiences, we have developed some suggested conversation openers for professionals to reach out for the first time to their local Latino community. These questions are designed to neutralize formality and focus on the important contribution of the local leaders. Although these questions may be helpful, they must also be adapted to your specific circumstances.

1. I work with (identify school/program) and have noticed (identify issue of concern) and was wondering if this is something I could help with?

2. We want to be able to help but I do not know enough about the local Latino culture. Could you help me? What could you share with me about our community to help me better understand the issues faced by Latino families here?

3. Are there specific cultural factors I need to remember when trying to address this issue? Are there people in the Latino community here that you know that may be willing to help me with this?

4. What do I need to remember when trying to involve families in this process? How could I approach parents about this sensitive issue without offending them or disrespecting them? and How might I be able to get to know the local Latino community better?

These questions are merely a start but it is our belief that most professionals if approached in this manner will be pleased with your agency/school's investment in reaching out and will respond positively.

The final suggestion we have for engaging local leaders in program development is to follow-up with the local Latino leaders to report on what you have 
done with the information they have shared with you. Their feedback is as crucial to making a program that is relevant to your local community than any other source of information. We believe that the more you explicitly draw from research and community leaders when developing community-based programs, the more success you will have.

\section{SUGGESTIONS FOR FUTURE RESEARCH/INTERVENTION}

The broad diversity of Latinos within American society underscores the need for future research that can articulate and advance the implementation of community- based interventions from a multidisciplinary perspective. In fact, it is clear that many social service and community agencies are trying to be more culturally competent (Hernandez et al., 1998), but are primarily attempting to achieve this only through culturally adapting these programs (Uttal, 2006). Similarly, although much has been written in the education literature about the language learning and curriculum development of children of immigrants in the United States (Gutierrez et al., 2001; Laliberty, 2001; Worthy, 2006), these studies fail to take a community- based intervention approach in bridging the sociocultural differences that must be understood before having successful engagement of parents and family members in their children's education.

Further research needs to be done to develop systematic methods of identifying important characteristics that are specific to a given community, which would allow professionals to move beyond generalizations, and develop communitybased educational programming. In fact, cultural competency goes deeper than translation and adapting components of a previously existing program (Utall, 2006). Rather, community characteristics will move teachers and educators toward ways that they can approach work that builds on and strengthens children's vital relationships with families and communities (Ada \& Zubizarreta, 2001), while subsequently inviting the parents to share their wisdom and experience as valuable contributors to the educational community programs. Additional research needs to be done to assess the differential impact of community-based programs verses culturally adapted and culturally specific programs.

One way that this can be accomplished is educating community leaders, gatekeepers, educators, and stakeholders of the importance of community involvement in designing and implementing educational and community programs (Castro et al., 2004; Gutierrez-Mayka \& Contreras-Neira, 1998). In so doing, parents and community leaders can feel a part of this process, thus being empowered with a voice in this design. It is our belief that this process will help in bridging many of the unique barriers and sociocultural differences that impede Latino families from using educational and community programs.

Next, the education literature is clear that teachers often hold negative perceptions of Latino families because of their lack of involvement in their children's education (Ada \& Zubizarreta, 2001: Palermo et al., 2007). Consequently, future research in the education literature would benefit from assessing the changes in teachers perspective as they engage effectively with Latino families from a community-based perspective. These findings may build a stronger case that educational interventions need to shift from a client-centered perspective to a holistic community-based orientation (Uttal, 2006) to help overcome misperceptions that are created from barriers of engagement when working with Latino families. 
Additional research needs to assess the amount of time it takes for teachers and or educators to create community partnership within the local community in meaningful and effective ways. It is believed that culturally effective programs need to be seen as different from a service provider-client relationship to one of community residents' (Gutierrez-Mayka \& Contreras-Neira, 1998). As this is accomplished, the power is decentralized to the local level, which creates a sense of empowerment in the minority community that is likely to affect the process of engagement. In addition, educators and human service professionals will also save time by being involved in the local community. For example, it is believed that attendance or utility of educational and human service programs among Latinos will be greater. In addition, as program designers build relationships in the community, they will simultaneously address issues of trust, which is imperative to building effective community programs.

\section{ADDITIONAL IMPLICATIONS}

This model has utility for curriculum and teaching as well. Many of the students in family and consumer sciences plan on working with individuals in the community in some capacity. The principles and steps in this model may be easily adapted to teach students methods of engaging individuals from other cultures in community-based programs. Teaching this model to university students in a field where they will directly work with the Latino community would provide a good foundation for their future work.

Although this article was designed to outline the model for use with engagement in the Latino community, it is believed that the principles contained therein have utility when engaging other cultural groups as well. Clearly, the types of adaptations and specifications would be different but the need to adapt program delivery and program content is consistent for other cultural groups. It is suggested that an extensive reviews of literature regarding how to modify both the delivery and the content of a program for a specific population be performed before contacting the specific cultural group. In so doing, one will have a better understanding of cultural norms and values that is necessary when working with different groups.

When conducting research on community-based programs, it will become necessary for researchers to make explicit the local modifications that were made and the justification for those modifications. Replication of research evaluating these types of programs will need to assess programmatic similarity in terms of the methods used to identify the community-based needs and compare those methods to ones used in other studies. It is the method of this final step in program development that must be evaluated, not the outcome of the content developed. Further research needs to be done to test the capacity to compare programs based on methodological approaches and not content delivery.

\section{SUMMARY}

This theoretical article presents a model for engaging Latino families in outreach educational programs. The need for effective programs is clear in the educational and human services literature. The model is developed from existing 
literature in human services and adapted for family and consumer science professionals. An additional step was highlighted from the existing literature that involves reaching out to the local Latino community. It is our experience that this step is key to successful community-based programs with Latinos. Engaging diverse populations in programming is a difficult but important task for program developers. It is our hope that the model and subsequent suggestions will be useful in orienting professionals in the process of developing community-based and culturally specific programs.

\section{REFERENCES}

Ada, A. F., \& Zubizarreta, R. (2001). Parent narratives: The cultural bridge between Latino parents and their children. In M. L. Reyes \& J. J. Halcon (Eds.), The best for our children: Critical perspectives on literacy for Latino students (pp. 229-245). New York: Teachers College Press.

Alegría, M., Canino, G., Ríos, R., Vera, M., Calderón, J., Rusch, D., et al. (2002). Mental health care for Latinos: Inequalities in use of specialty mental health services among Latinos, African Americans, and non-Latino Whites. Psychiatric Services, 53, 1547-1555.

Altermatt, E. R. (2007). Coping with academic failure: Gender differences in student's self-reported interaction with family members and friends. Journal of Early Adolescence, 2, 479-508.

Arroyo, W. (1998). Immigrant children and families. In M. Hernandez \& M. R. Isaacs (Eds.), Promoting cultural competence in children's mental health services (pp. 251-268). Baltimore: Brookes.

Auerbach, S. (2004). Engaging Latino parents in supporting college pathways: Lessons from a college access program. Journal of Hispanic Higher Education, 3, 125-145.

Bachelor, A., \& Horvath, A. (1999). The therapeutic relationship. In M. A. Hubble, B. L. Duncan, \& S. D. Miller (Eds.), The heart and soul of change: What works in therapy (pp. 133-178). Washington, DC: American Psychological Association.

Bartolome, L. I., \& Balderrama, M. V. (2001). The need for educators with political and ideological clarity: Providing our children with "The Best." In M. L. Reyes \& J. J. Halcon (Eds.), The best for our children: Critical perspectives on literacy for Latino students (pp. 48-64). New York: Teachers College Press.

Bean, R. A., Perry, B. J., \& Bedell, T. M. (2001). Developing culturally competent marriage and family therapists: Guidelines for working with Hispanic families. Journal of Marital and Family Therapy, 27, 43-54.

Bitar, G. W. (2007). The in-session self-disclosure experiences of Mexican American men who are on federal probation with co-occurring mental health and substance use issues. Unpublished doctoral dissertation, Texas Tech University, 2007.

Castro, F. G., Barrera, M., \& Martinez, C. R. (2004). The cultural adaptation of prevention intervention tensions between fidelity and fit. Prevention Science, 5, 41-45.

Cauce, A. M., \& Domenech-Rodriguez, M. (2002). Latino families: Myths and realities. In J. Contreras, K. Kearns, \& A. Neal-Barnett (Eds.), Latino children and families in the United States (pp. 3-25). New York: Praeger.

Chrispeels, J. H., \& Rivero, E. (2001). Engaging Latino families for student success: How parent education can reshape parents' sense of place in the education of their children. Peabody Journal of Education, 76(2), 119-169.

Civil, M., Bratton, J., \& Quintos, B. (2005). Parents and mathematics education in a Latino community: Redefining parental participation. Multicultural Education, 13, 60-64.

Cooper, C. R. (2002). Five bridges along students' pathways to college: A developmental blueprint of families, teachers, counselors, mentors, and peers in the Puente project. Educational Policy, 16, 607-621. 
Cross, T. L., Bazron, B. J., Dennis, K. W., \& Isaacs, M. R. (Eds.). (1989). Towards a culturally competent system of care: Vol. I. A monograph on effective services for minority children who are severely emotionally disturbed. Washington, DC: Georgetown University, Child Development Center, Child and Adolescent Service System Program, Technical Assistance Center.

De Gaetano, Y. (2007). The role of culture in engaging Latino parents' involvement in school. Urban Education, 42, 145-162.

Delgado, M. (1998). Linking schools, human services and community: A Puerto Rican perspective. Social Work in Education, 20(2), 121-130.

Diaz, E., \& Flores, B. (2001). Teacher as sociocultural, sociohistorical mediator. In M. L. Reyes \& J. J. Halcon (Eds.), The best for our children: Critical perspectives on literacy for Latino students (pp. 29-47). New York: Teachers College Press.

Falicov, C. J. (1998). Latino families in therapy: A guide to multicultural practice. New York: Guilford.

Flores, M. T., \& Carey, G. (2000). Family therapy with Hispanics: Toward appreciating diversity. Boston: Allyn \& Bacon.

Folsom, D. P., Gilmer, T., Barrio, C., Moore, D. J., Bucardo, J., Lindamer, L. A., et al. (2007). A longitudinal study of the use of mental health services by persons with serious mental illness: Do Spanish- speaking Latinos differ from English-speaking Latinos and Caucasians? American Journal of Psychiatry, 164, 1173-1180.

Gonzales, N. A., Tein, J. Y., Sandler, I. N., \& Friedman, R. J. (2001). On the limits of coping: Interaction between stress and coping for inner-city adolescents. Journal of Adolescent Research, $16,372-395$.

Greenbaum, S. D. (1998). The role of ethnography in creating linkages with communities: Identifying and assessing neighborhoods' needs and strengths. In M. Hernandez \& M. R. Isaacs (Eds.), Promoting cultural competence in children's mental health services (pp. 119-148). Baltimore: Brookes.

Gross, D., Julion, W., \& Fogg, L. (2001). What motivates participation and dropout among lowincome urban families of color in a prevention intervention? Family Relations, 50, 246-254.

Gutierrez, K. D., Baquedano-Lopez, P., \& Alvarez, H. H. (2001). Literacy as hybridity: Moving beyond bilingualism in urban classrooms. In M. L. Reyes \& J. J. Halcon (Eds.), The best for our children: Critical perspectives on literacy for Latino students (pp. 122-141). New York: Teachers College Press.

Gutierrez-Mayka, M., \& Contreras-Neira, R. (1998). A culturally receptive approach to community participation in system reform. In M. Hernandez \& M. R. Isaacs (Eds.), Promoting cultural competence in children's mental health services (pp. 133-148). Baltimore: Brookes.

Hernandez, M., Isaacs, M. R., Nesman, T., \& Burns, D. (1998). Perspectives on culturally competent systems of care. In M. Hernandez \& M. R. Isaacs (Eds.), Promoting cultural competence in children's mental health services (pp. 1-25). Baltimore: Brookes.

Ho, M. K., Rasheed, J. M., \& Rasheed, M. N. (2004). Family therapy with ethnic minority (2nd ed.). Thousand Oaks, CA: Sage.

Hurtado, A. (1995). Variations, combinations, and evolutions: Latino families in the United States. In R. E. Zambrana (Ed.), Understanding Latino families: Scholarship, policy and practice (pp. 40-81). Thousand Oaks, CA: Sage.

Laliberty, E. A. (2001). Hooked on writing: Linking literacy to students' lived experiences. In M. L. Reyes \& J. J. Halcon (Eds.), The best for our children: Critical perspectives on literacy for Latino students (pp. 142-150). New York: Teachers College Press.

Lambert, M. J. (1992). Implication of outcome research for psychotherapy integration. In J. C. Norcross \& M. Goldstein (Eds.), Handbook of psychotherapy integration (pp. 94-129). New York: Basic Books.

La Roche, M. J. (2002). Psychotherapeutic considerations in treating Latinos. Harvard Review of Psychiatry, 10, 115-122.

Machen, S. M., Wilson, J. D., \& Notar, C. E. (2005). Parental involvement in the classroom. Journal of Instructional Psychology, 32(1), 13-16.

Madding, C. C. (2002). Socialization practices of Latinos. In A. Brice (Ed.), The Hispanic child: Speech, language, culture and education (pp. 68-84). Boston: Allyn \& Bacon. 
Maldonado-Mulina, M. M., Reyes, N. A., \& Espinosa-Hernandez, G. (2006). Prevention research and Latino families: Resources for researchers and practitioners. Family Relations, $55,403-414$.

Massey-Stokes, M., \& Lanning, B. (2003). Commentary: School health and community involvement: Making a difference in the prevention of child abuse and neglect. Adolescent and Family Health, 2, 154.

National Center for Education Statistics. (2001). Dropout rates in the United States: 2000. Washington, DC: U.S. Department of Education.

Ortiz, V. (1995). The diversity of Latino families. In R. E. Zambrana (Ed.), Understanding Latino families: Scholarship, policy and practice (pp. 18-39). Thousand Oaks, CA: Sage.

Palermo, F., Hanish, L. B., Martin, C. L., Fabes, R. A., \& Reiser, M. (2007). Preschoolers' academic readiness: What role does the teacher-child relationship play? Early Childhood Research Quarterly, 22, 407-422.

Powell, D. R. (1995). Including Latino fathers in parent education and support programs: Development of a program model. In R. E. Zambrana (Ed.), Understanding Latino families: Scholarship, policy and practice (pp. 85-106). Thousand Oaks, CA: Sage.

Quezada, R. L., Diaz, D. M., \& Sanchez, M. (2003). Involving Latino parents. Leadership, Sept/ Oct, 32-38.

Quiocho, A. M. L., \& Daoud, A. M. (2006). Dispelling myths about Latino parent participation in schools. Educational Forum, 70, 255-267.

Riggs, N. R., \& Medina, C. (2005). The "Generacion Diez" after-school program and Latino parent involvement with schools. Journal of Primary Prevention, 26, 471-484.

Santisteban, D. A., Szapocznik, J., Perez-Vidal, A., Kurtines, W. M., Murray, E. J., \& LaPerriere, A. (1996). Efficacy of intervention for engaging youth and families into treatment and some variables that may contribute to differential effectiveness. Journal of Family Psychology, 10, $35-44$.

Shorris, E. (1992). Latinos: A biography of the people. New York: Norton.

Sugunro, O. A. (2001). Toward multiculturalism: Implications of multicultural education for schools. Multicultural Perspectives, 3(3), 19-33.

Szapocznik, J., \& Prado, G. (2007). Negative effects on family functioning from psychosocial treatments: A recommendation for expanded safety monitoring. Journal of Family Psychology, 21, 468-478.

Turner, W. T., Wieling, E., \& Allen, W. D. (2004). Developing culturally effective family-based research programs: Implications for family therapists. Journal of Marital \& Family Therapy, 30, 257-270.

U.S. Census Bureau. (2001). Overview of race and Hispanic origin: Census 2000 brief. Retrieved January 21, 2008, from http://www.census.gov/prod/2001pubs/c2kbr01-1.pdf

U.S. Census Bureau. (2003). United States foreign-born population. Retrieved March 1, 2008, from http:// www.census.gov/population/www/socdemo/foreign/reports.html

Uttal, L. (2006). Organizational cultural competency: Shifting programs for Latino immigrants from a client- centered to a community based orientation. American Journal of Community Psychology, 38, 251-262.

Valdés, G. (1996). Con respeto: Bridging the distances between culturally diverse families and schools: An ethnographic portrait. New York: Teachers College Press.

Vega, W. A. (1995). The study of Latino families: A point in departure. In R. E. Zambrano (Ed.), Understanding Latino families: Scholarship, policy and practice (pp. 3-17.). Thousand Oaks, CA: Sage.

Von Secker, C. E., \& Lissitz, R. W. (1999). Estimating the impact of instructional practices on student achievement in science. Journal of Research in Science Teaching, 36, 1110-1126.

Weaver, S. W. (2007). Cultivating connections with parents. Clearing House, 81(1), 5-7.

Worthy, J. (2006). Voces: Community, parents, teachers, and students: Como si le falta un brazo: Latino immigrant parents and the cost of not knowing English. Journal of Latinos and Education, 5, 139-154. 